\title{
UPAYA MENINGKATKAN KEMAMPUAN BERPIKIR KRITIS SISWA PADA MATERI BENTUK ALJABAR MELALUI PENDEKATAN CONTEXTUAL TEACHING AND LEARNING (CTL) BERBANTU SOFTWARE ALGEBRATOR DI KELAS VII-3 SMP NEGERI 18 KOTA TANGERANG SELATAN
}

\author{
Widya Apriliyanii', Andi Sessu' ${ }^{2)}$, Asih Miatun ${ }^{3)}$ \\ 1) Universitas Muhammadiyah Prof. DR. Hamka, Jln. Tanah Merdeka No. 20, Jakarta \\ Timur; widyaapriliyani27@yahoo.com \\ 2) Universitas Muhammadiyah Prof. DR. Hamka, Jln. Tanah Merdeka No. 20, Jakarta \\ Timur; dr_andi_sessu@yahoo.com \\ 3) Universitas Muhammadiyah Prof. DR. Hamka, Jln. Tanah Merdeka No. 20, Jakarta \\ Timur; asihmiatun@gmail.com
}

\begin{abstract}
This study aims to determine an increase in students' critical thinking skills in mathematics by using the Contextual Teaching and Learning (CTL) approach assisted by Algebrator Software in class VII-3 students of SMP Negeri 18 The City of South Tangerang in Semester 1 of the 2019/2020 academic year. The research method used was classroom action research (CAR) with a cycled learning model through four stages in each cycle, namely the planning stage, the implementation phase, the observation phase, and the reflection phase. The results showed that the average value of students' critical thinking skills before the action was 29.61 with the KKM achievement percentage of $0 \%$. After taking action using the Contextual Teaching and Learning (CTL) approach assisted by Algebrator Software students obtained an average value of students' critical thinking skills in the first cycle of 48.82 with a KKM achievement percentage of $39.47 \%$, still not meeting the research target. After making improvements, the average value of students' critical thinking skills obtained in the second cycle was 71.32 with the KKM achievement percentage of $81.58 \%$. The results of the study concluded that through the Contextual Teaching and Learning (CTL) approach assisted by Algebrator Software can improve the critical thinking skills of students in class VII-3 of SMP Negeri 18 The City of South Tangerang.
\end{abstract}

Keywords: Contextual Teaching and Learning (CTL) approach, Algebrator Software, The Ability to Critical Thinking

Euclid, p-ISSN 2355-1712, e-ISSN 2541-4453, Vol. 7, No. 2, pp. 77- 147 CLembaga Penelitian Universitas Swadaya Gunung Jati (UGJ), Cirebon. 


\section{Pendahuluan}

Kemampuan berpikir kritis diperlukan dalam pembelajaran matematika karena dapat meningkatkan keaktifan yang lebih terarah. Kemampuan berpikir kritis merupakan kemampuan yang akan digunakan untuk mengintegrasikan konsep yang diterima dari proses pembelajaran di sekolah dengan masalah yang akan dihadapi pada kehidupan sehari-hari (Hutagalung, 2013: 10).

Dalam berpikir kritis terdapat indikator yang digunakan sebagai acuan dalam membuat tes untuk mengukur kemampuan berpikir kritis yang dimiliki seseorang. Ennis (Ratnasari, 2019: 25-26) mengungkapkan bahwa terdapat enam elemen dasar dalam berpikir kritis yaitu FRISCO, yaitu Focus (fokus), Reason (alasan), Inference (menarik kesimpulan), Situation (situasi), Clarity (kejelasan), dan Overview (periksanaan atau tinjauan).

Dalam penelitian ini, kemampuan berpikir kritis mengacu pada lima elemen dasar yang telah diungkapkan oleh Ennis dengan indikator, yaitu indikator Focus, indikator Reason, indikator Inference, indikator Situation, dan indikator Overview.

Berdasarkan hasil tes dan evaluasi PISA tahun 2015 (Nurlaeli, Noornia, dan Wiraningsih, 2018: 146) menunjukkan bahwa Indonesia berada pada posisi 62 dari 70 negara dalam hal kemampuan berpikir kritis. Sejalan dengan hal tersebut, Hendrayana (Noordyana, 2016: 121) juga menyatakan bahwa nilai rata-rata kemampuan berpikir kritis dari siswa SMP kurang dari 50\% dari skor ideal, sehingga kemampuan berpikir kritis siswa harus ditingkatkan.

Penelitian dilakukan di kelas VII-3 SMP Negeri 18 Kota Tangerang Selatan. Nilai rata-rata ulangan harian siswa di kelas VII-3 sebesar 74,92. Nilai tersebut menunjukkan bahwa kemampuan belajar matematika siswa di kelas VII-3 lebih rendah dibandingkan kelas lainnya, maka dari itu kelas VII-3 dipilih sebagai subjek penelitian. Selanjutnya peneliti melakukan tes pra siklus untuk mengetahui kemampuan berpikir kritis siswa di kelas VII-3. Berdasarkan hasil tes pra siklus tersebut, diketahui bahwa semua siswa di kelas VII-3 mempunyai kemampuan berpikir kritis yang sangat rendah yaitu sebesar $0 \%$ atau tidak ada satu pun siswa yang mendapatkan nilai KKM dengan nilai KKM yang ditentukan sebesar 75 pada tes kemampuan berpikir kritis yang diberikan.

Dari uraian di atas, di perlukan pemilihan ataupun penggunaan pendekatan pembelajaran yang efektif agar dapat meningkatkan kemampuan berpikir 
kritis siswa. Salah satu pendekatan pembelajaran yang bisa membantu meningkatkan kemampuan berpikir kritis siswa yaitu pendekatan Contextual Teaching and Learning (CTL). CTL merupakan salah satu dari banyak pendekatan pembelajaran yang dapat digunakan oleh para pengajar. Pendekatan kontekstual atau CTL adalah pendekatan pembelajaran yang mengaitkan antara materi yang dipelajari dengan konteks kehidupan seharihari (Nuridawani, Munzir, dan Saiman, 2015: 62).

Terdapat 8 tahapan pembelajaran CTL yang disebutkan oleh Lestari dan Yudhanegara (2017: 39) dalam bukunya, yaitu Grouping, Modelling, Questioning, Learning Community, Inquiry, Contructivism, Authentic Assessment, dan Reflection.

Berdasarkan penelitian yang dilakukan oleh Barus (2018: 23) menyimpulkan bahwa nilai rata-rata peningkatan kemampuan berpikir kritis siswa yang diberikan pembelajaran dengan menggunakan pendekatan kontekstual lebih tinggi dibandingkan siswa yang diberikan pembelajaran dengan menggunakan pembelajaran konvensional. Hal ini sejalan dengan penelitian yang dilakukan oleh Suwanjal (2016: 66) yang menyimpulkan bahwa peningkatan kemampuan siswa yang memperoleh pembelajaran dengan pendekatan kontekstual lebih baik daripada siswa yang memperoleh pembelajaran secara konvensional. Dengan demikian, penggunaan pendekatan Contextual Teaching and Learning (CTL) akan memberikan peningkatan yang signifikan terhadap kemampuan berpikir kritis siswa. Selain itu, Shanti, Sholihah, dan Abdullah (2018: 56) menjelaskan hasil dalam penelitiannya bahwa rata-rata kemampuan berpikir kritis siswa dengan kelas CTL lebih tinggi dibandingkan rata-rata kemampuan berpikir kritis siswa dengan kelas problem posing.

Upaya agar pelaksanaan pembelajaran lebih menarik siswa untuk berperan aktif dalam proses pembelajaran, maka dalam pelaksanaan pendekatan Contextual Teaching and Learning (CTL) bisa lebih berinovatif sesuai dengan perkembangan IPTEK yaitu dengan menggunakan software pembelajaran. Dengan menggunakan software pembelajaran diharapkan dapat menarik minat siswa untuk mempelajari matematika lebih dalam. Dalam penelitian ini, peneliti akan menggunakan software pembelajaran matematika untuk lebih mempermudah peneliti dan siswa dalam proses pembelajaran. Pada penelitian ini peneliti akan menggunakan software matematika Algebrator. Yulian (2016: 23-24) dalam penelitiannya menemukan bahwa berbantuan software Algebrator dapat mempengaruhi tingginya minat, motivasi, dan aktivitas pembelajaran siswa terutama pada pembelajaran matematika. Selain itu, menurut penelitian yang dilakukan oleh Umbara dan Rahmawati 
(2018: 19) menyebutkan bahwa kemampuan pemahaman matematik siswa yang pembelajarannya menggunakan berbantuan software Algebrator lebih baik daripada siswa yang tidak menggunakan software Algebrator. Algebrator merupakan alat bantu mengajar materi matematika berupa kalkulator aljabar yang dapat dimanfaatkan sebagai pengganti papan tulis untuk menjelaskan langkah demi langkah dalam penyelesaian masalah aljabar. Selain dapat menyelesaikan masalah yang berkaitan dengan materi aljabar, Algebrator juga bisa digunakan untuk menyelesaikan masalah yang berkaitan dengan materi bilangan, persamaan, fungsi, matriks, statistik, dll.

Berdasarkan uraian di atas, peneliti akan melakukan penelitian dengan judul “Upaya Meningkatkan Kemampuan Berpikir Kritis Siswa Melalui Pendekatan Contextual Teaching and Learning (CTL) Berbantu Software Algebrator di kelas VII-3 SMP Negeri 18 Kota Tangerang Selatan".

\section{Metodologi Penelitian}

Pada penelitian ini subjek penelitian tindakan kelas adalah siswa kelas VII-3 tahun pelajaran 2019/2020. Karakteristik yang ingin diteliti adalah kemampuan berpikir kritis siswa dengan pendekatan Contextual Teaching and Learning (CTL) berbantu software Algebrator yang digunakan peneliti dalam pembelajaran di kelas.

Pada penelitian ini peneliti akan menggunakan desain penelitian dengan model pembelajaran bersiklus pada Penelitian Tindakan Kelas. Pada model ini, terdapat empat tahapan yang ada dalam satu siklus PTK, yaitu (1) perencanaan; (2) pelaksanaan; (3) pengamatan; dan (4) refleksi. Rancangan pelaksanaan penelitian tindakan kelas ini dapat dilihat pada Gambar 3.2 (Arikunto, Suhardjono, dan Supardi, 2015: 42), yaitu:

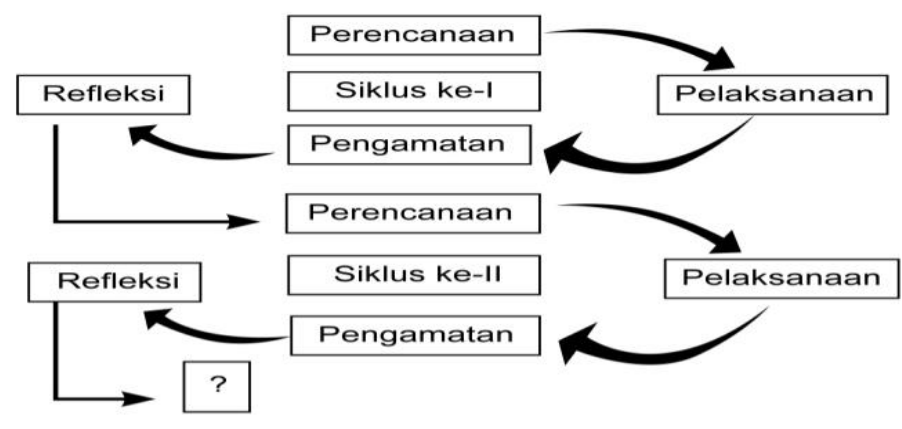

Gambar 3.2

Alur PTK Model Pembelajaran Bersiklus 
Jika pada akhir hasil dari tahap refleksi sudah memenuhi indikator yang telah ditentukan, maka peneliti tidak perlu melakukan siklus berikutnya. Sedangkan jika pada tahap akhir refleksi belum memenuhi indikator yang telah ditentukan maka peneliti kembali lagi pada tahap perencanaan atau melakukan siklus berikutnya hingga pada akhir tahap refleksi dilakukan dan telah memenuhi indikator yang telah ditentukan.

Data kemampuan berpikir kritis siswa yang diperoleh berasal dari skor hasil tes kemampuan berpikir kritis siswa. Setiap instrumen pengumpulan data tersebut telah diuji validasi oleh kedua dosen pembimbing dan diuji validasi di sekolah lain selain sekolah yang akan digunakan sebagai subjek penelitian.

\section{Hasil Pembahasan}

Pembelajaran matematika dengan menggunakan Pendekatan Contextual Teaching and Learning (CTL) berbantu software Algebrator terbukti dapat meningkatkan kemampuan berpikir kritis siswa di kelas VII-3 SMP Negeri 18 Kota Tangerang Selatan. Berikut ini merupakan tabel mengenai peningkatan kemampuan berpikir kritis siswa:

Tabel 4.1

Data Nilai Rata-Rata dan Persentase Pencapaian

\begin{tabular}{|c|l|c|c|c|}
\hline \multirow{2}{*}{ No. } & \multirow{2}{*}{ Kriteria } & \multicolumn{3}{|c|}{ Persentase } \\
\cline { 3 - 5 } & & Pra Siklus & Siklus I & Siklus II \\
\hline 1 & Nilai rata-rata kelas & 29,61 & 48,82 & 71,32 \\
\hline 2 & Sudah mencapai KKM & $0 \%$ & $39,47 \%$ & $81,58 \%$ \\
\hline
\end{tabular}

Dari data yang telah di sajikan di atas, dapat disajikan dalam bentuk diagram sebagai berikut:

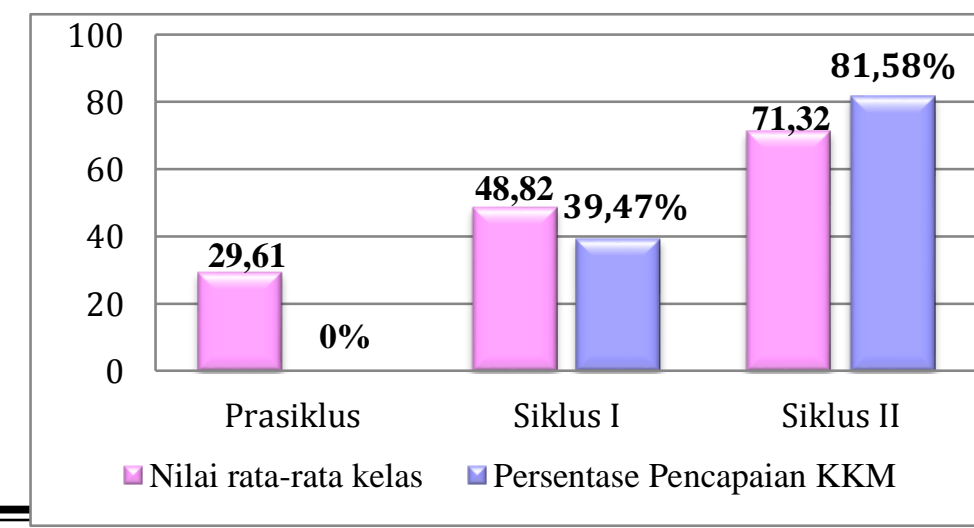

Euclid, p-ISSN 2355-1712, e-ISSN 2541-4453, Vol. 7, No. 2, pp. 77- 147 CLembaga Penelitian Universitas Swadaya Gunung Jati (UGJ), Cirebon. 


\section{Gambar 4.1}

\section{Diagram Presentase Data Nilai Rata-Rata Pencapaian KKM}

Berdasarkan gambar diagram di atas, dapat menjelaskan bahwa kemampuan berpikir kritis siswa mengalami peningkatan dari tes pra siklus yang hanya memperoleh nilai rata-rata kelas sebesar 29,61 dengan persentase pencapaian kriteria ketuntasan minimal (KKM) siswa sebesar 0\%. Setelah dilakukannya tindakan dalam proses pembelajaran dengan menggunakan pendekatan contextual teaching and learning (CTL) berbantu software algebrator, pada siklus I mengalami peningkatan nilai rata-rata kelas menjadi 48,82 dengan persentase pencapaian KKM siswa meningkat menjadi 39,47\%, kemudian pada siklus II terlihat pula peningkatan kemampuan berpikir kritis siswa. Pada siklus II nilai rata-rata kelas mengalami peningkatan menjadi 71,32 dengan persentase pencapaian KKM siswa menjadi 81,58\%. Berdasarkan data tersebut, dapat diketahui bahwa proses pembelajaran dengan menggunakan Pendekataan Contextual Teaching and Learning (CTL) berbantu software algebrator dapat meningkatkan kemampuan berpikir kritis siswa di kelas VII-3 SMP Negeri 18 Kota Tangerang Selatan. Hal ini sejalan dengan penelitian yang dilakukan oleh Barus (2018: 23); Suwanjal (2016: 66); serta Shanti, Sholihah, dan Abdullah (2018: 56) yang menyimpulkan bahwa penggunaan pendekatan CTL dalam proses pembelajaran matematika dapat meningkatkan kemampuan berpikir kritis siswa.

\section{Simpulan}

Berdasarkan penelitian tindakan kelas (PTK) yang dilakukan di kelas VII-3 SMP Negeri 18 Kota Tangerang Selatan, maka dapat disimpulkan bahwa pendekatan Contextual Teaching and Learning (CTL) berbantu Software Algebrator dapat meningkatkan kemampuan berpikir kritis siswa pada materi bentuk aljabar di SMP Negeri 18 Kota Tangerang Selatan. Adanya peningkatan dapat dilihat dari hasil data yang didapatkan sebelum maupun sesudah dilakukan tindakan. Nilai rata-rata siswa pada data awal 29,61 dengan siswa yang mencapai KKM memperoleh persentase $0 \%$ kemudian peneliti melakukan tindakan pada siklus I memperoleh rata-rata nilai 
matematika kelas VII-3 sebesar 48,82 dengan persentase siswa yang mencapai KKM sebesar 39,47\%. Pada siklus II memperoleh rata-rata nilai matematika siswa sebesar 71,32 dengan persentase siswa yang mencapai KKM sebesar $81,58 \%$.

\section{Daftar Pustaka}

Arikunto, S., Suhardjono, dan Supardi. (2015). Penelitian Tindakan Kelas. Jakarta: Bumi Aksara.

Barus, E. M. Br. 2018. Pengaruh Penerapan Pendekatan Kontekstual Terhadap Kemampuan Berpikir Kritis Matematika Siswa SMP ST. Thomas 1 Medan. Cartesius: Jurnal Pendidikan Matematika, 1(1), 10-24.

Hutagalung, A. M. 2013. Efek Model Pembelajaran Inquiry Training Berbasis Media Komputer Terhadap Keterampilan Proses Sains dan Kemampuan Berpikir Kritis Siswa. Jurnal Pendidikan Fisika, 2(2), 9-16.

Lestari, K. E., \& Yudhanegara, M. R. 2017. Penelitian Pendidikan Matematika (Panduan Praktis Menyusun Skripsi, Tesis, dan Laporan Penelitian dengan Pendekatan Kuantitatif, Kualitatif, dan Koombinasi Disertai dengan Model Pembelajaran dan Kemampuan Matematis). Bandung: PT Refika Aditama.

Noordyana, M. A. 2016. Meningkatkan Kemampuan Berpikir Kritis Matematis Siswa Melalui Pendekatan Metacognitive Instruction. Jurnal Pendidikan Matematika STKIP Garut, 5(2), 120-127.

Nuridawani, Munzir, S., \& Saiman. 2015. Peningkatan Kemampuan Penalaran Matematis dan Kemandirian Belajar Siswa Madrasah Tsanawiyah (MTs) melalui Pendekatan Contextual Teaching and Learning (CTL). Jurnal Didaktik Matematika, 2(2), 59-71.

Nurlaeli, Noornia, A., \& Wiraningsih, E. D. 2018. Pengaruh Model Pembelajaran Problem Based Learning Terhadap Kemampuan Berpikir Kritis Matematis Siswa Ditinjau Dari Adversity Quotient. Fibonacci Jurnal Pendidikan Matematika dan Matematika, 4(2), 145-154.

Ratnasari, S. A. 2019. Situation-Based Learning (SBL) untuk Meningkatkan Kemampuan Berpikir Kritis Matematis Siswa SMP. Jurnal Edukasi Sebelas April, 3(1), 21-31.

Shanti, W. N., Sholihah, D. A., dan Abdullah, A. A. 2018. Pengaruh Pendekatan Problem Posing dan CTL Terhadap Kemampuan Berpikir Kritis dalam Pembelajaran Matematika Bagi Siswa SMA. Jurnal Karya Pendidikan Matematika, 5(2), 49-57.

Suwanjal, U. 2016. Pengaruh Penerapan Pendekatan Kontekstual Terhadap Kemampuan Berpikir Kritis Matematis Siswa SMP. Aksioma (Jurnal Pendidikan Matematika FKIP Univ. Muhammadiyah Metro), 5(1), 61-67.

Euclid, p-ISSN 2355-1712, e-ISSN 2541-4453, Vol. 7, No. 2, pp. 77- 147 CLembaga Penelitian Universitas Swadaya Gunung Jati (UGJ), Cirebon. 
Umbara, U., dan Rahmawati, I. 2018. Pembelajaran Matematika Berbantuan Software Algebrator untuk Meningkatkan Kemampuan Pemahaman Matematis Siswa. Jurnal Elemen, 4(1), 9-19.

Yulian, V. N. 2016. Meningkatkan Kemampuan Pemecahan Masalah Matematis Siswa Melalui Metode Pembelajaran Metode Inkuiri Berbantuan Software Algebrator. JPPM (Jurnal Penelitian dan Pembelajaran Matematika), 9(1), 20-24. 